\title{
Haemostatic changes during surgery for primary brain tumours
}

Keith Yu-Ching Goh, Wai-Chiu Tsoi, Chi-Shun Feng, Nicholas Wickham, Wai Sang Poon

Neurosurgical Unit, Department of

Surgery

K Y-C Goh

W S Poon

Haematology

Laboratory and Blood

Bank, Department of

Anatomical and

Cellular Pathology

Wai-Chiu Tsoi

Chi-Shun Feng

Department of Clinical Oncology, Prince of

Wales Hospital, The

Chinese University of

Hong Kong

$\mathrm{N}$ Wickham

Correspondence to:

Dr WS Poon, Neurosurgical

Unit, Department of

Surgery, Prince of Wales

Hospital, The Chinese

University of Hong Kong,

Shatin, New Territories,

Hong Kong.

Received 20 May 1996 and in revised form 4 March 1997

Accepted 18 March 1997

\begin{abstract}
Objective-Primary brain tumours may be associated with coagulation disorders which can pose intraoperative and postoperative management difficulties. The aim was to evaluate the coagulation profile of patients with brain tumours undergoing surgery using thromboelastography (TEG) in combination with simple laboratory tests.

Methods-Fifty adult patients with primary brain tumours larger than $4 \mathrm{~cm}$ in maximum diameter and no history of coagulation disorders were studied in a prospective, observational manner over a one year period. Preoperative, intraoperative, and postoperative measurements included haemoglobin concentration, platelet count, prothrombin and partial thromboplastin times, fibrin(ogen) degradation product concentration, D-dimer concentration, and TEG.
\end{abstract}

Results-Eleven patients (22\%) had abnormal intraoperative TEGs, of whom six (12\%) subsequently developed haematomas requiring surgical evacuation. The coagulopathy seemed to be hyperfibrinolysis in two cases (4\%) and disseminated intravascular coagulation in four $(8 \%)$. There was no preoperative difference in reaction time ( $R$ time) for clot formation between the non-haematoma and haematoma groups(mean 11.44 (SD 3.42) $v 12.33$ (2.50) $\mathrm{min}, P=0.46)$. However, when other preoperative indices were compared, in the non-haematoma group, $K$ time (time to reach a clot amplitude of $20 \mathrm{~mm})$ was shorter (6.72 (2.15) $v 10.56$ (3.50) $\mathrm{min}, \mathbf{P}=0.001$ ), rate of clot growth (å) was faster $\left(43.67^{\circ}(7.53) v 27.11^{\circ}(5.42)\right.$, $P<0.0001)$ and maximum amplitude of clot strength (MA) was greater (52.64 (7.85) $v 40.33(6.59) \mathrm{mm}, P<0.001)$. Intraoperatively, $R$ time was significantly shortened in the non-haematoma group, (7.67 (1.78) $\mathrm{min}, \mathbf{P}<0.0001)$ unlike the haematoma group (10.67 (1.58) minutes, $\mathbf{P}=\mathbf{0 . 1 1}$ ).

Conclusions-Although these results indicate a general hypercoagulability during brain tumour surgery, in certain cases, a predisposition towards hypocoagulability may exist even before surgery, detectable only when the physical characteristics of clot formation are studied by TEG. Judicious replacement of clotting factors, platelets, and antifibrinolytic agents should be considered intraoperatively if the TEG is abnormal, without waiting for laboratory test results.

\section{(F Neurol Neurosurg Psychiatry 1997;63:334-338)}

Keywords: coagulopathy; fibrinolysis; haematomas; primary tumours

In neurosurgery, haemorrhagic abnormalities and postoperative haematomas uniformly result in poor outcome, with one recent series reporting $55 \%$ severe disability or mortality at six months, and only $13 \%$ with good outome. ${ }^{1}$ In the 1960s, Morozov first reported the possibility that brain tumour factors were responsible. ${ }^{2}$ Most investigators currently think that hyperfibrinolysis, either primary or secondary to a disseminated intravscular coagulation type condition, is the mechanism responsible for these haemostatic abnormalities. ${ }^{13}$ The pathophysiology is thought to involve release of plasminogen activator factors from tumour cells, or tissue factors from injured brain parenchyma during surgery. ${ }^{45}$

The aim of this study was to investigate the changes in haemostatic profile occurring during surgery for large primary brain tumours, using a combination of physical and laboratory methods to assess coagulation characteristics. By early intraoperative detection and identification of the haemostatic abnormality, appropriate measures might be initiated to prevent postoperative complications.

\section{Patients and methods}

Over a one year period, all newly diagnosed patients with primary brain tumours larger than $4 \mathrm{~cm}$ in maximum diameter on CT were entered into the study. Excluded were those with a history of haematological or coagulation disorders, those taking anticoagulant therapy, and those with chronic disease-for example, liver cirrhosis or renal failure.

The standard haemostatic profile was determined preoperatively by measurement of the following laboratory tests of coagulation : haemoglobin, platelet count, prothrombin (PT) and partial thromboplastin times (PTT), fibrin(ogen) degradation products (FDP), and $\mathrm{D}$ dimers. The physical characteristics of clot formation for each patient were measured at the same time by thromboelastography (TEG) using the Thromboelastograph coagulation analyser (Hellige, GMBH 1990, West Germany). Four main indices of clot formation were measured on the TEG : (1) R time (reaction time to clot formation; normal 11.8 (2.4) min); (2) K time (time to achieve clot strength 


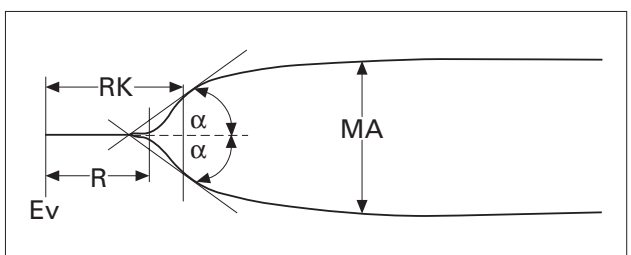

Figure 1 Thromboelastography profile. $R=$ reactive time; $R K=$ clot time $; A=$ maximum amplitude; $\alpha=$ angle; event=event marker.

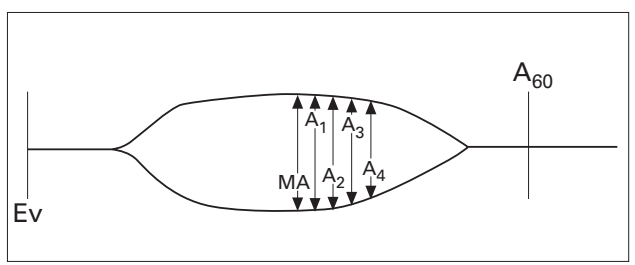

Figure 2 Hyperfibrinolysis profile. Ev=event marker; $M A=$ maximum amplitude; $A=$ amplitude at 60 minutes, $A_{1}, A_{2}, A_{3}$, and $A_{4}$ amplitudes at five minute $(10 \mathrm{~mm})$ intervals after $M A$

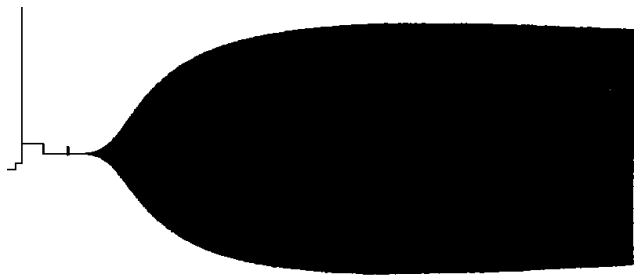

Figure 3 Normal thromboelastography.

of $20 \mathrm{~mm}$ amplitude; normal : $5.3(1.4) \mathrm{min}$ ); (3) MA (maximum amplitude; normal : 54 (5.6) $\mathrm{mm}$ ), and (4) angle å (rate of clot growth) (normal : $36(7.4)^{\circ}$ (fig 1). With this combination of laboratory results and TEG, the haemostatic characteristics of the clot could be analysed and any deficiencies-for example, platelet dysfunction, clotting factor deficiency, or hyperfibrinolysis (fig 2), identified. (Figure 3 shows a normal TEG appearance.) More complex tests of platelet function, clotting factor concentrations, and plasminogen activator assays were considered but not performed because it was our intention to correlate commonly used and easily available laboratory tests with the TEG and clinical features.

Tests were performed preoperatively on the day of surgery, intraoperatively (two hours into surgery), and postoperatively the day after surgery. Routine blood sampling was from the central venous pressure (internal jugular) line. All patients had intracranial pressure monitoring in the intensive care unit postoperatively by

Table 1 Tumour type, haematoma incidence, and thromboelastogram (TEG) abnormality

\begin{tabular}{|c|c|c|c|c|}
\hline Tumour type & $\begin{array}{l}\text { Cases } \\
\text { (n) }\end{array}$ & $\begin{array}{l}\text { Cases with } \\
\text { haematoma }\end{array}$ & $\begin{array}{l}\text { Surgery } \\
\text { required }\end{array}$ & $\begin{array}{l}\text { TEG } \\
\text { abnormality }\end{array}$ \\
\hline Meningioma & 31 & $1(\mathrm{TBH})$ & 1 & 3 (DIC) \\
\hline Acoustic neuroma & 7 & $4(2 \mathrm{ICH}, 1 \mathrm{EDH}, 1 \mathrm{TBH})$ & 3 & 4 (1 PF, $3 \mathrm{DIC})$ \\
\hline Glioma & 5 & $1(\mathrm{TBH})$ & & 1 (DIC) \\
\hline Haemangioblastoma & 2 & $1(\mathrm{TBH})$ & 1 & 1 (DIC) \\
\hline Pineal gland & 2 & & & \\
\hline Pituitary & 1 & & & \\
\hline Neurocytoma & 1 & $1(\mathrm{EDH})$ & & 1 (DIC) \\
\hline Craniopharyngioma & 1 & $1(\mathrm{EDH})$ & 1 & $1(\mathrm{PF})$ \\
\hline
\end{tabular}

$\overline{\mathrm{EDH}}=$ Extradural haematoma; $\mathrm{ICH}=$ intracerebral haematoma; $\mathrm{TBH}=$ tumour bed haematoma; $\mathrm{PF}=$ primary fibrinolysis; $\mathrm{DIC}=$ disseminated intravascular coagulation. an intraventricular catheter. Brain CT was performed if the intracranial pressure was raised above $30 \mathrm{~mm} \mathrm{Hg}$. A haematoma was considered significant if the volume was more than 30 $\mathrm{ml}$ or the intracranial pressure was not controllable by osmotherapy, ventilation, or CSF drainage. In such cases, reoperation was necessary to evacuate the haematoma. Clinical follow up at three, six, and 12 months was obtained.

\section{STATISTICAL METHODS}

All laboratory results and TEG indices were recorded and analysed using Statview 4.2 for Macintosh. The values were expressed as mean (SD) and comparisons made using a paired $t$ test within groups and unpaired $t$ test between groups. Results were considered significant at $\mathrm{P}<0.05$.

\section{Results}

Over a 13 month period from November 1993 to December 1994, 50 patients were studied.The age range was from 15 to 69 (mean 42) years. Twenty one patients were male and 29 were female.There were 31 meningiomas, seven acoustic neuromas, five gliomas, two haemangioblastomas, two pineal gland tumours, one pituitary tumour, one craniopharyngioma, and one intraventricular neurocytoma (table 1). All patients underwent total or near total $(>90 \%)$ tumour resection.

Nine patients (18\%) developed postoperative haematomas, of which three were extradural haematomas, four were tumour bed haematomas, and two were intracerebral haematomas unrelated to tumour site. Six patients (12\%) required reoperation, comprising two with extradural haematoma, two with tumour bed haematoma, and two with intracerebral haematoma. In the remaining three cases, the intracranial pressure was closely monitored and the haematoma size followed up until resolution without requiring surgery.

The non-haematoma group (group $\mathrm{NH}$ ) was compared with the haematoma group (group $\mathrm{H}$ ) in terms of platelet count, PT, PTT, TEG indices, and FDP and $\mathrm{D}$ dimer concentrations.

\section{PREOPERATIVE COMPARISONS}

All 50 patients were found to have preoperative platelet counts, PT, and PTT within normal values and there were no differences between groups $\mathrm{NH}$ and $\mathrm{H}$ for platelet count, PT, FDP, and $\mathrm{D}$ dimer concentrations (table 2). However, PTT was longer in group $\mathrm{H}$ (37.2 $(0.95) \mathrm{s})$ than in group $\mathrm{NH}(33.94$ (3.19) s) $(P=0.0055)$, but within normal values. For TEG indices, there was no difference in $\mathrm{R}$ time between the two groups (11.43 (3.42) and 12.33 (2.50) min; $\mathrm{P}=0.46$ ). However, $\mathrm{K}$ time, $\mathrm{a}$, and MA values in group $\mathrm{H}$ reflected highly significant hypocoagulability compared with group $\mathrm{NH}$ (table 3 ).

\section{INTRAOPERATIVE COMPARISONS}

Intraoperative hypocoagulability in group $\mathrm{H}$ was evidenced by a significant fall in platelet count, no shortening of PTT, no reduction in $\mathrm{R}$ time, and a highly significant reduction in MA 
Table 2 Comparison of platelet counts, PT, PTT, FDP, and D dimer concentrations within and between groups $H$ and NH

\begin{tabular}{|c|c|c|c|c|c|}
\hline Variables and groups & $\begin{array}{l}\text { Preop * } \\
(A)\end{array}$ & $\begin{array}{l}\text { Intraop * } \\
\text { (B) }\end{array}$ & $\begin{array}{l}\text { Postop } \\
(C)\end{array}$ & $\begin{array}{l}A v B \\
\text { (Pvalue) }\end{array}$ & $\begin{array}{l}B v C \\
\text { (Pvalue) }\end{array}$ \\
\hline \multicolumn{6}{|c|}{ Platelets` $\left(\right.$ normal $\left.120-400 \times 10^{9} / 1\right)$ : } \\
\hline NH & $186.9(36.6)$ & $178.2(44.7)$ & $188.5(39.7)$ & 0.5 & 0.44 \\
\hline $\mathrm{H}$ & $161.6(15.9)$ & $98 \quad(21.9)$ & $162.2(35.7)$ & 0.0001 & 0.0003 \\
\hline Difference ( $\mathrm{P}$ value) & 0.06 & $<0.0001$ & 0.1 & & \\
\hline \multicolumn{6}{|l|}{$\mathrm{PT}^{\star}$ (normal 10-12 min): } \\
\hline $\mathrm{NH}$ & $11.7(1.19)$ & $10.6(1.13)$ & $10.5(1.18)$ & 0.0013 & 0.98 \\
\hline $\mathrm{H}$ & $12.4(0.69)$ & $11.3(0.58)$ & $11.1(0.64)$ & 0.003 & 0.45 \\
\hline \multirow{2}{*}{\multicolumn{6}{|c|}{$\mathrm{PTT}^{\star}($ normal $27-37 \mathrm{~min})$ : }} \\
\hline & & & & & \\
\hline $\mathrm{NH}$ & $33.9(3.19)$ & $31.6(2.8)$ & $30.9(2.66)$ & 0.011 & 0.37 \\
\hline $\mathrm{H}$ & $37.2(0.95)$ & $36.3(2.14)$ & $35.2(1.94)$ & 0.25 & 0.3 \\
\hline Difference ( $\mathrm{P}$ value) & 0.0055 & $<0.0001$ & 0.0001 & & \\
\hline \multicolumn{6}{|l|}{ FDP (normal <10 $\mu \mathrm{g} / \mathrm{ml}$ ): } \\
\hline $\mathrm{NH} \dagger$ & $<10$ & $>10$ & $<10$ & 0.08 & 0.07 \\
\hline $\mathrm{H} \dagger$ & $<10$ & $<200$ & $>10<40$ & 0.08 & 0.15 \\
\hline Difference ( $P$ value) & 0.76 & 0.22 & 0.007 & & \\
\hline \multicolumn{6}{|c|}{ D dimer (normal $<0.5 \mu \mathrm{g} / \mathrm{ml})$ : } \\
\hline $\mathrm{NH} \dagger$ & $1-2$ & $2-4$ & $1-2$ & 0.14 & 0.11 \\
\hline $\mathrm{H}+$ & $<1$ & $>8$ & $2-4$ & 0.007 & 0.1 \\
\hline Difference ( $P$ value) & 0.39 & 0.06 & 0.001 & & \\
\hline
\end{tabular}

*Values expressed as means (SD); tvalues expressed as range.

Table 3 Comparison of TEG variables during perioperative period, within and between groups $H$ and NH

\begin{tabular}{|c|c|c|c|c|c|}
\hline TEG variables and groups & $\begin{array}{l}\text { Preop } \\
(A)^{\star}\end{array}$ & $\begin{array}{l}\text { Intraop } \\
(B)^{\star}\end{array}$ & $\begin{array}{l}\text { Postop } \\
(C)^{\star}\end{array}$ & $\begin{array}{l}A v B \\
\text { (P value) }\end{array}$ & $\begin{array}{l}B \text { v } C \\
(P \text { value })\end{array}$ \\
\hline \multicolumn{6}{|c|}{ R time ${ }^{\star}$ (normal $11.8(2.4) \mathrm{min}$ ): } \\
\hline $\mathrm{NH}$ & $11.43(3.42)$ & $7.66(1.78)$ & $7.64(2.07)$ & $<0.0001$ & 0.95 \\
\hline $\mathrm{H}$ & $12.33(2.5)$ & $10.67(1.58)$ & $8.11(1.69)$ & 0.11 & 0.0044 \\
\hline Difference ( $P$ value) & 0.46 & $<0.0001$ & 0.53 & & \\
\hline \multicolumn{6}{|c|}{$\mathrm{K}_{\text {time }}^{\star}($ normal $5.3(1.4) \mathrm{min})$ : } \\
\hline NH & $6.72(2.15)$ & $5.97(1.96)$ & $5.43(3.09)$ & 0.12 & 0.21 \\
\hline $\mathrm{H}$ & $10.56(3.50)$ & $10(5.87)$ & $7(3.32)$ & 0.81 & 0.20 \\
\hline Difference (P value) & 0.0001 & 0.0008 & 0.052 & & \\
\hline \multicolumn{6}{|l|}{$\mathrm{a}^{\star}\left(\right.$ normal 36 $\left.(7.4)^{\circ}\right)$} \\
\hline NH & $43.67(7.53)$ & $42.18(9.78)$ & $43.64(9.87)$ & 0.45 & 0.52 \\
\hline $\mathrm{H}$ & $27.11(5.42)$ & $30(11.34)$ & $37.67(8.16)$ & 0.50 & 0.12 \\
\hline Difference (P value) & $<0.0001$ & 0.002 & 0.099 & & \\
\hline \multicolumn{6}{|c|}{$\mathrm{MA}^{\star}$ (normal $\left.54(5.6) \mathrm{mm}\right)$ : } \\
\hline $\mathrm{NH}$ & $52.64(7.85)$ & $46.69(9.07)$ & $47.97(8.54)$ & 0.0027 & 0.52 \\
\hline $\mathrm{H}$ & $40.33(6.59)$ & $31(6.73)$ & $43.44(5.46)$ & 0.009 & 0.0005 \\
\hline Difference ( $P$ value) & $<0.0001$ & $<0.0001$ & 0.14 & & \\
\hline
\end{tabular}

^Values expressed as mean (SD).

(tables 2 and 3). By contrast, group $\mathrm{NH}$ showed some hypercoagulability in that there was a significant shortening of PT and PTT, and a highly significant reduction in $\mathrm{R}$ time (table 3).

POSTOPERATIVE COMPARISONS

In group $\mathrm{H}$, there was a return to a mild hypercoagulable state, with a significant rise in platelet count, reduction in $\mathrm{R}$ time, and increase in MA (tables 2 and 3). PT and PTT were also shortened, but this did not reach significance $(\mathrm{P}=0.45$ and 0.29 respectively). In group $\mathrm{NH}$, the hypercoagulable state remained unchanged, with maintenance of platelet count, PT, PTT, R time, $\mathrm{K}$ time, å, and MA (tables 2 and 3). FDP and $\mathrm{D}$ dimer concentrations were, however, significantly higher in the postoperative period in group $\mathrm{H}$ (table 2).

Figure 4 shows the trends in TEG indices of both groups during the perioperative period. Decreasing $\mathrm{R}$ and $\mathrm{K}$ times with increased a and MA values in group NH indicate a somewhat hypercoagulable state compared with group $\mathrm{H}$.

HAEMOSTATIC ABNORMALITIES IN GROUP $\mathrm{H}$ In the nine patients who developed postoperative haematomas, the abnormalities found intraoperatively were a significant reduction in MA (mean 40.33 v $31.00 \mathrm{~mm}, \mathrm{P}=0.009$ ), a highly significant fall in platelet count (mean $161.6 v 98 \times 10^{9} / 1, \mathrm{P}<0.0001$ ), and a significant increase in $\mathrm{D}$ dimer concentrations (mean $<1 v$ $>8 \mu \mathrm{g} / \mathrm{ml}, \mathrm{P}=0.007)$. These results suggested the possibility of a disseminated intravascular coagulation type mechanism, which might have predisposed this group of patients to haematomas.

In two of these nine cases, a hyperfibrinolytic profile appeared intraoperatively on TEG, with a reduction of MA from 35 to $25 \mathrm{~mm}$ within 60 minutes in one case and from 55 to $27 \mathrm{~mm}$ in the other (fig 5). This suggested that the primary clot was formed to a certain MA, but underwent clot lysis to a much smaller MA within 60 minutes. In both these cases, D dimer and FDP concentrations were considerably raised $(>8 \mu \mathrm{g} / \mathrm{ml}$ and $40-200 \mu \mathrm{g} / \mathrm{ml}$ respectively). Tranexamic acid, an antifibrinolytic agent, was given in both cases with improvement clinically and on TEG.

By contrast, the other seven cases showed a prolonged small MA intraoperatively (mean $31.00 \mathrm{~mm}$ ) even after 60 minutes, indicating that there was poor clot strength, either from platelet or clotting factor deficiency, without abnormal lysis. These appearances were consistent with disseminated intravascular coagulation and responded to platelet and fresh frozen plasma replacement. 

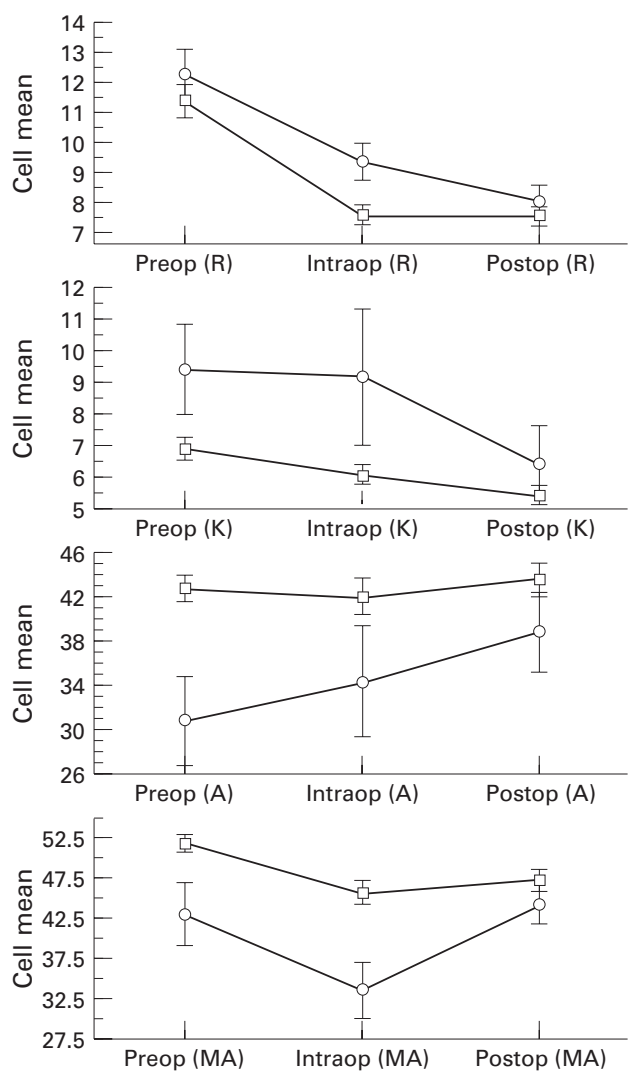

Figure 4 Trends (mean (SEM)) in thromboelastography variables during perioperative period. $R$ (min); $K$ (min); $A$ (a); $M A(\mathrm{~mm})$.

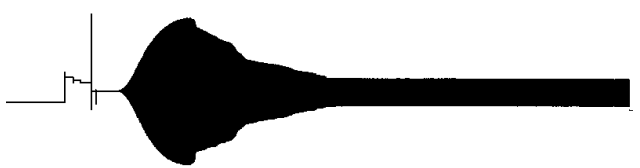

Figure 5 Thromboelastography of patient with hyperfibrinolysis.

OUTCOME

Of the six patients in whom repeat surgery for haematoma evacuation was required, the mortality rate was $16.7 \%(1 / 6)$. Two patients were severely disabled at six months, whereas three had mild disability according to the Glasgow outcome scale. The remaining three cases with non-evacuated haematomas were discharged home within one month of surgery when repeat imaging showed resolution of the haematoma and outcome was considered good.

\section{Discussion}

The occurrence of haemostatic abnormalities in surgery has been described since the 1930s. ${ }^{6}$ Trauma, malignancy, sepsis, even anxiety have all been cited as possible causes of coagulopathy. ${ }^{7}$ Intracranial surgery in particular, whether for trauma, ${ }^{9}$ vascular pathology, ${ }^{10}$ or malignancy, ${ }^{112}$ has been shown to be associated with a higher incidence of coagulation disorders compared with general surgical procedures. ${ }^{13}$ The mechanism is thought to be due to the release into the circulation of thromboplastic substances from injured brain, which is the richest source of thromboplastins in the body, and that the incidence of these coagulopathies is related to the severity or extent of brain tissue injury, sometimes as a consequence of surgery. ${ }^{3}{ }^{14}$

In cancer patients, haemostatic abnormalities have been described before any surgical procedure and include both hypercoagulable as well as hypocoagulable states. Patients with brain tumours are no different, and thromboembolic complications may occur ${ }^{15}$ as may disseminated intravascular coagulation, hyperfibrinolysis, and haemorrhage. ${ }^{16}{ }^{17}$ The role of intrinsic tumour factors, mainly plasminogen activators, has been implicated and investigated. ${ }^{17} 19$

Unlike other types of surgery, neurosurgery requires haemostasis to be achieved without ligature. Impaired haemostasis predisposes the patient to postoperative haematomas, which can have devastating effects in terms of morbidity and mortality. One series has reported an overall mortality of $32 \%$, with $55 \%$ of those with postoperative haematoma being dead or severely disabled at six months. ${ }^{1}$

In this series of patients in whom the coagulation profile has been studied during the perioperative period by simple laboratory tests and physical tests of clot function, several points of interest have emerged. Whereas the TEG is well established in extracranial surgery such as liver transplantation ${ }^{20}$ and cardiac surgery, ${ }^{21}$ its use in major neurosurgical procedures has not been previously described. The principle of operation of the TEG is that it provides a visual representation of the viscoelastic changes occurring in a coagulating sample of blood and is sensitive to all the interacting cellular and plasma components in blood that may affect the rate, structure, and breakdown of the clot. $^{22}{ }^{23}$ The TEG analyser is a machine in which a piston is suspended in a rotating cuvette containing a small volume $(35 \mathrm{ml})$ of whole blood to be analysed. As coagulation proceeds, fibrin strands attach to the piston, allowing shear elasticity of the forming clot to be measured as the fibrin transfers rotating motion from the piston to a paper tracing. This physical method follows clot formation through fibrin cross linking to retraction and lysis in one sample of blood. We have found that it provides valuable insight, when combined with standard laboratory tests, into the understanding of the haemostatic changes occurring during surgery. In assessing platelet function for example, it may show poor platelet aggregation and function despite seemingly normal platelet counts. Similarly, coagulation factor deficiencies which may not be evident in terms of abnormal PT and APTT values until they are more than $50 \%$ reduced, may be reflected by abnormal TEG indices. The test is simple to perform and has the advantage of providing immediate information to the operating team because the machine can be located in the operating theatre.

Secondly, as previous investigators have found, brain tumour surgery may result in a hypercoagulable state. ${ }^{15}$ Iberti et al showed a significant reduction in PTT and bleeding times, which was suggested to be a consequence of 
perioperative dehydration and hyperosmolality. ${ }^{11}$ Our data were consistent with these findings in that there was generally a significant reduction in PT, PTT, and R time intraoperatively, which was maintained in the first 24 hours after surgery and did not return to preoperative values. We suggest that this faster clot formation may be a normal physiological and haemostatic response to surgical trauma.

Thirdly, however, when the group of patients who developed haematomas (group $\mathrm{H}$ ) was compared with the group that did not (group $\mathrm{NH}$ ), significant differences were detected preoperatively, intraoperatively, and postoperatively. There was no significant reduction in $\mathrm{R}$ time between the preoperative and intraoperative stages in group $\mathrm{H}$ patients, unlike group $\mathrm{NH}$ in which $\mathrm{R}$ times were shorter (fig 4). Furthermore, in group $\mathrm{H}$, preoperative $\mathrm{K}$ time, å, and MA showed significant hypocoagulability compared with group $\mathrm{NH}$ (fig 4). Postoperatively, FDP and D dimer concentrations were also significantly higher in group $\mathrm{H}$ compared with group $\mathrm{NH}$, implying increased disseminated intravascular coagulation type mechanisms or fibrinolysis. As tumour site, size, and surgical accessibility in groups $\mathrm{H}$ and $\mathrm{NH}$ were considered comparable, these differences suggested a predisposition towards hypocoagulability and an increased likelihood of postoperative haematomas, which might not be solely related to surgical or technical factors.

What are possible risk factors? Although our results do not cast light on a possible hypothesis, we suggest that large tumours, tumour type, tumour factors, residual tumour size, brain thromboplastins, and ethnic characteristics may be contributary. Mattock and Crockard, for example, have described a disseminated intravascular coagulation type coagulopathy in three patients with large acoustic neuromas. ${ }^{24}$ Meningiomas have also been associated with haemorrhagic diathesis and raised concentrations of tissue plasminogen activator. ${ }^{17}{ }^{18}$ Furthermore, ethnic Chinese seem predisposed to haemorrhagic complications as evidenced by the higher incidence of haemorrhagic cerebrovascular accidents in Hong Kong and the People's Republic of China compared with the West. ${ }^{25} 26$

\section{Conclusion}

We suggest, therefore, that TEG is useful both in the preoperative assessment of patients with large brain tumours and in the intraoperative stage for monitoring of the haemostatic profile. In the event of coagulopathies encountered intraoperatively, early replacement of clotting factors and platelets should be started even before laboratory test results are known. However, to explain and understand why coagulopathies occur in certain cases and not others, basic cellular mechanisms of tumours and the effects of tumorous factors may have to be investigated on a molecular level and on a wider scale.

This work was presented in part at the 9th Asian-Australasian Congress of Neurological Surgeons, 5-10 November, 1995, Taipei, Taiwan. It was supported by a Direct Grant from the Chinese University of Hong Kong Grant Committee.

1 Palmer JD, Sparrow OC, Iannotti F. Postoperative hematoma. A 5-year survey and identification of avoidable risk factors. Neurosurgery 1994;35:1061-5.

2 Morozov W. The coagulation and anticoagulative blood systems in brain tumors of a supratentorial localization. $Z \mathrm{~h}$ tems in brain tumors of a supratentorial localization.

3 Palmer JD, Francis DA, Roath OS, Francis JL, Iannotti F. Palmer JD, Francis DA, Roath OS, Francis JL, Iannotti F.
Hyperfibrinolysis during intracranial surgery. Effect of high dose aprotinin. F Neurol Neurosurg Psychiatry 1995;58:1046.

4 Olson JD, Kaufman HH, Moake J, O'Gorman TW, Hoots $\mathrm{K}$, Wagner $\mathrm{K}$, et al. The incidence and significance of hemostatic abnormalities in patients with head injuries. Neurosurgery 1989;24:825-32.

5 Singh VP, Jain D, Mohan R, Bhatia R, Bhargava M. Hemostatic abnormalities in brain tumors. Acta Neurochir (Wien) 1990;102:103-7.

6 Macfarlane RG. Fibrinolysis following operation. Lancet $1937 ; \mathrm{i}: 10-2$.

7 Latner AL. Anxiety as a cause of fibrinolysis. Lancet 1947;i: $194-5$.

8 Macfarlane RG, Biggs R. Observations on fibrinolyis. Spontaneous activity associated with surgical operations, taneous activity associated with
trauma, etc. Lancet $1946 ;$ ii: $862-4$.

9 Kaufman HH, Moake JL, Olson JD, Miner ME, duCret RP, Kaufman HH, Moake JL, Olson JD, Miner ME, duCret RP,
Pruessner JL, Gildenberg PL. Delayed and recurrent Pruessner JL, Gildenberg PL. Delayed and recurrent
intracranial hematomas related to disseminated intravascular clotting and fibrinolysis in head injury. Neurosurgery lar clotting and

10 Fujii Y, Tanaka R, Takeuchi S, Koike T, Minakawa T, Sasaki $O$. Serial changes in hemostasis after intracranial surgery. Neurosurgery 1994;35:26-33.

1 Iberti TJ, Miller M, Abalos A, Fischer EP, Post KD, Benjamin E, et al. Abnormal coagulation profile in brain tumor patients during surgery. Neurosurgery 1994;34:38995.

12 McGee EE, Bernell WR. Acute fibrinolysis following craniotomy and removal of metastatic tumor of the cerebellum. f Neurosurg 1970;32:578-80.

13 Van der Sande JJ, Veltkamp JJ, Bouwhuis-Hoogerwerf ML. Haemostasis and intracranial surgery. $\mathcal{F}$ Neurosurg $1983 ; 58$ : 693-8.

14 Prasad KSM, Sharma BS, Marwaha N, Sarode RS, Kak VK. Hemostatic derangements in patients with intracranial tumors. Br f Neurosurg 1994;8:695-702.

15 Sawaya R, Glas-Greenwalt P. Post-operative venous thromboembolism and brain tumours. $\mathcal{F}$ Neurooncol 1992;14: $127-34$

16 Sawaya R, Donlon JA. Chronic disseminated intravascular coagulation and metastatic brain tumor. A case report and review of literature. Neurosurgery 1983;12:580-4

17 Oka K, Tsuda H, Kamikaseda K, Nakamura R, Fukui M, Nouzuka Y, Sueishi K. Meningiomas and hemorrhagic diathesis. F Neurosurg 1988;69:356-60.

18 Jones NR, Blumbergs PC. Intracranial hemorrhage from meningiomas, a report of 5 cases. $\mathrm{Br} \mathcal{F}$ Neurosurg 1989;3:691-8.

19 Tsuda H, Oka K, Noutsuka Y, Sueishi K. Tissue type plasminogen activator in patients with intracranial meningiomas. Thromb Haemostas 1988;60:508-13.

20 Howland WS, Castro EB, Fortner JB, Gould P. Thromboelastographic monitoring during extensive hepatic surgery. Arch Surg 1974;108:605-8.

21 Spiess BD, Tuman KJ, McCarthy RJ, Ivankovich AD. Thiess BD, Tuman KJ, McCarthy RJ, Ivankovich AD.
Thromboelastography as an indicator of postcardiopulmonary bypass coagulopathies. $\mathcal{F}$ Clin Monitoring 1987;3:25-20

22 Saleem A, Blifeld C, Saleh SA, Yawn DH, Mace ML, Shwartz M, Crawford ES. Viscoelastic measurement of clot formation. A new test of platelet function. Ann Clin Lab Sci 1983;13:115-24.

23 Howland WS, Schweizer O, Gould RN. A comparison of intraoperative measurements of coagulation. Current Research in Anesthesiology and Analgesia 1974;53:663-7.

24 Mattock C, Crockard A. Does intravascular coagulation contribute to operative mortality for large acoustic tumors. $\exists$ Neurol Neurosurg Psychiatry 1986;49:699-701.

25 Huang CY, Yu YL, Woo KW, Chan FL. Cerebral hemorrhage in an urban Chinese population. Funct Neurol 1986;1:213-21.

26 Shi FL, Hart RG, Sherman DG, Tegeler CH. Stroke in the People's Republic of China. Stroke 1989;20:1581-5. 